https://doi.org/10.48009/1_iis_2005_107-113

\title{
INVESTIGATION OF THE INTEGRATION OF SAP ENTERPRISE SOFTWARE IN BUSINESS CURRICULA
}

\author{
Roger L. Hayen, Central Michigan University, roger.hayen@cmich.edu \\ Frank A. Andera, Central Michigan University, frank.andera@cmich.edu
}

\begin{abstract}
The integration of enterprise software (ES) into college of business curricula began in 1996. Since then, a number of universities have achieved various levels of integration of ES into their curriculum. A framework for curriculum integration considers courses taken by all students, the functional business area students (excluding information systems (IS)), and the IS program area students. Using this framework, the integration of courses is multi-dimensional. The most frequently reported integration undertaking is the inclusion of ES in the introductory IS course, which is required of most business students. The results indicate that the MIS academic area has a lead in the integration of ES into its curriculum. This includes both the largest number of courses and courses with the greatest amount of ES content.
\end{abstract}

Keywords: Enterprise software, ES, enterprise resource planning, ERP, SAP R/3 System, curriculum integration, curriculum framework, curriculum design

\section{INTRODUCTION}

The purpose of this research is to provide information about aggregate experiences in integrating enterprise software into business curricula. Enterprise software encompasses enterprise resource planning (ERP) systems [18], which are comprehensive, packaged software that integrate the complete range of business processes and functions to provide a holistic view of business within a single information system (IS) technology architecture. These systems exhibit both a breadth of functionality and tight integration across that functionality. They encompass the core transaction processing activities of a business enterprise, which is more than just resource planning. To indicate this expansive capability, this software is referred to here as enterprise software (ES). Vendors of ES include SAP AG, PeopleSoft, Oracle, J.D. Edwards, and Baan. The widespread used of ES has increased the need for students with knowledge of this software. In an effort to meet this need, SAP AG initiated the SAP University Alliance Program (UAP) in North America in 1996 [2, 13]. That program now encompasses approximately 200 universities. The primary purpose of the SAP UAP is to make students more knowledgeable while concurrently providing faculty with the opportunity to employ cutting-edge information technology [12]. This has resulted in SAP R/3 being the most popular ES used to support the integration of ES into college and university curricula.

The integration of ES into academic curricula poses many choices. The proliferation of research in integrating ES into the business curriculum [1] indicates that some integration is appropriate. The underlying questions then are: What is being done in the various courses of ES curriculum integrations? What might be done at your academic institution? Typically, the goal is to use ES technology as a "tool" to help teach business concepts [11]. Differences of experiences in including ES conceptual and experiential learning in business curricula represent alternatives that can be considered in choosing a roadmap which best matches learning objectives to your 
curriculum. The purpose here is to report findings regarding experiences of a number of institutions. The goal is to assist you in assessing options to determine where your curriculum is and to help determine its future direction. This is examined in the order of frameworks, curricula survey, and research analysis.

\section{FRAMEWORKS}

A framework is useful in that it assists in gaining a perspective on the field of ES and serves as a powerful means of providing focus and improving the effectiveness of a curriculum. For ES, frameworks have been postulated at several levels that encompass individual courses, curricula within the business discipline, and the extent of integration within courses. Curriculum integration frameworks provide an infrastructure for evaluating the integration of ES into curricula. The integrated ES model curriculum framework [13] arranges courses into three primary course categories or groups which are All Students, IS Program, and Functional Area. All Students are the common body of knowledge (CBK) courses, required of all business students, and other courses in ES designed for all students, independent of their major. These would include accounting, introduction to business, introduction to information systems, and introduction to ES. IS Program courses are those specialized information technology and application design courses for both a major and minor in IS or MIS. Courses in this category are taken by both MIS majors and students in functional areas who desire an IS specialist competency or minor, and they frequently follow a general IS curriculum model [9]. Functional Areas courses are those that integrate ES applications with functional area concepts and meet a minimum content requirement for an ES component course, wherein ES concepts are entwined with the functional area knowledge. An example of this integration would be a human relations compensation course in which the cases that support the concepts are ES cases and include a hands-on ES component that supports compensation concepts. For this integration, it is likely that previously used paper-based read and analyze cases are replaced by the ES hands-on cases. Generally, students would follow this curriculum framework by taking initial classes in the All Students category and then proceed further, depending on their interest. Hawking et al [10] classify the ES curriculum developed by universities into four different approaches: 1) ERP training, 2) ERP via business processes, 3) information systems approach, and 4) ERP concepts. Further, they indicate universities may have any combination of these four approaches combined, resulting in a hybrid approach. Overall, their approaches can be mapped to the model curriculum framework of Hayen et al [13], where the approach is oriented to the primary course categories of the curriculum.

Antonucci et al [1] describe an ERP education deployment maturity model. First, they provide a guide for appraising the integration of ES within an institutions curriculum. Second, they present a perspective, which represents the extent of overall curriculum development in ES. Whereas the first dimension is relatively controllable within an academic institution, the second dimension is concerned with the development of curriculum by the overall educational community and is outside the control of an individual academic institution. Faculty and their university may contribute to the overall curriculum development within the business discipline; however, they have can exercise very little to no control over this. An the optimized level is attained when ES is integrated across the entire curriculum with each course containing some ES content. 
Applying the criteria established by SAP America, an ES component course is one in which 20 percent or more of the content is related to the concepts and/or applications of ES [6]. The extent of course integration can vary from just mentioning ES, SAP R/3 and ERP in one or two course lectures to the extent of encompassing the entire course, such as ERP Configuration. In this situation, the course easily could have 100 percent ES content through the combination of business concepts and hands-on experience in the course. A number of individual course endeavors have been undertaken [7, 14, 16, 20, 24]; however, the literature search did not reveal any curriculum effort where ES has reached an optimized level. Much remains to be done in the development of ES component courses and the creation of various course materials before that maturity is attained.

Overall, these frameworks provide three dimensions for evaluating ES curricula. These are the primary category area courses, the academic area courses, and the extent of ES course content.

\section{CURRICULA SURVEY}

The first 100 universities that became members of the SAP UAL were surveyed in order to evaluate their collective experiences in the integration of ES into business curricula. This initial group of UAL member universities was selected since they had some time to work on ES integration in their curricula. This permitted an evaluation of what has been done, rather than what was being planned. The investigation included measures of the level of ES integration into specific courses and into academic areas. Typically, an academic area represents a program of study which is a student's major within a business degree. Often, but not always, an academic area is associated with a separate department. So, overall, academic area and department housing the courses are the same. The survey collected data on both undergraduate and graduate programs. The specific research questions centered on:

1. Determining how ES has been integrated into existing curricula and programs of study at both the undergraduate and graduate levels.

2. Identifying the specific business courses and programs offered at these institutions.

3. Ascertaining student satisfaction with the ES content and deployment in these courses.

The respondents were asked to identify all of the courses within their respective programs that currently use the SAP R/3 software as their ES. This included course numbers or identifiers, course titles, academic areas or departments housing these courses, number of undergraduate or graduate students enrolled in the courses during the past year, percent of each course's ES content, and their students' overall satisfaction with the ES component of the course.

Using the frameworks presented above, the data from the respondents was reviewed and coded for the primary course categories and the academic areas. The three primary categories are All Students (A), MIS Students (M), and Functional Area Students (F). The six academic areas are Accounting (ACC), Finance (F), Management (MGT), Management Information Systems (MIS), Marketing (MKT), and Production and Operations Management (POM). These framework classifications together with the basic data collected on courses provided the overall data set for analysis. 


\section{RESEARCH ANALYSIS}

Thirty of the SAP UAL universities responded to the survey. Of these, 29 reported they are accredited by the Association to Advance Collegiate Schools of Business (AACSB)

International. The results indicate 12,280 students had taken courses that were supported with SAP R/3 software. The composition of theses students in terms of their class levels or standings are summarized in Figure 1. As shown, more than half the students represented were upper-level undergraduates. Students at this level are frequently enrolled in courses for their selected major or specialized program of study, rather than courses that are taken by all students pursing a business degree.

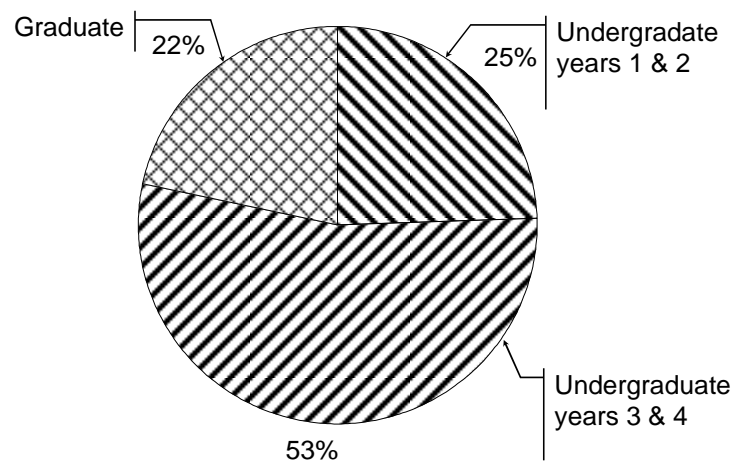

Figure 1. Student class level

Figure 2 shows student participation in the three primary categories (A, M, and F). Nearly half (46 percent) of the students were enrolled in courses in the functional academic business areas other than MIS. Figure 3 delineates the relative number of primary category area courses. This shows that only 5 percent of the courses were of the All students area. When this is compared to the 25 percent All students area number of students (Figure 2), it illustrates that the number of students enrolled in each course (an average of 382) is rather large compared to the other primary category areas. This average results from both multiple sections of the same course as well as large size sections, when compared to the other two primary category areas.

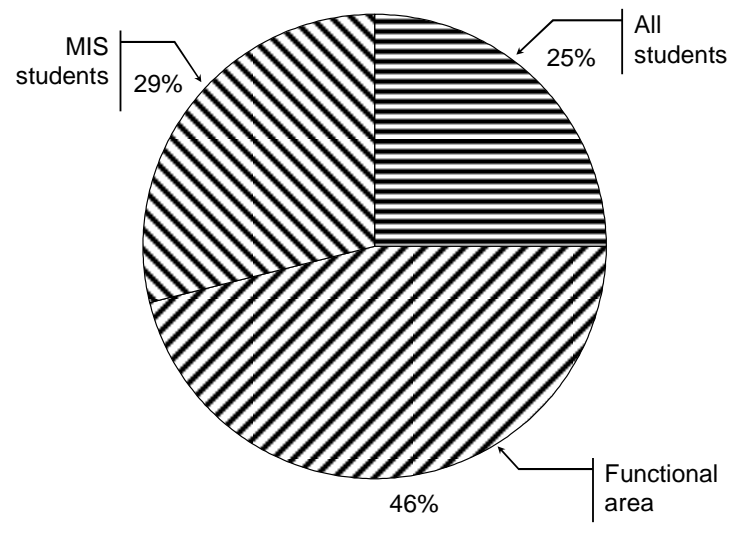

Figure 2. Primary category area students

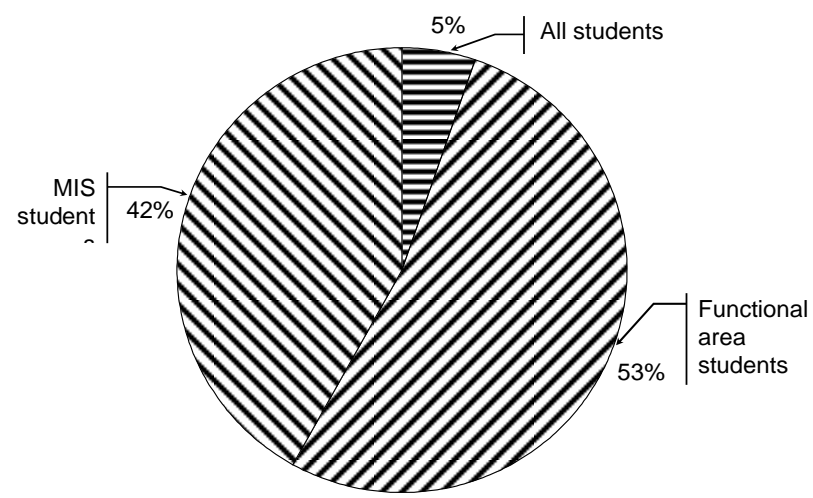

Figure 3. Primary category area courses 
The All students primary category area course are delivered by the MIS department or academic area. As a result, 47 percent of the courses are from MIS academic area. The 53 percent of the Functional Area courses can be further analyzed (Figure 4). Of these remaining courses, 43 percent are in the accounting area and 24 percent are in the production and operations management area.

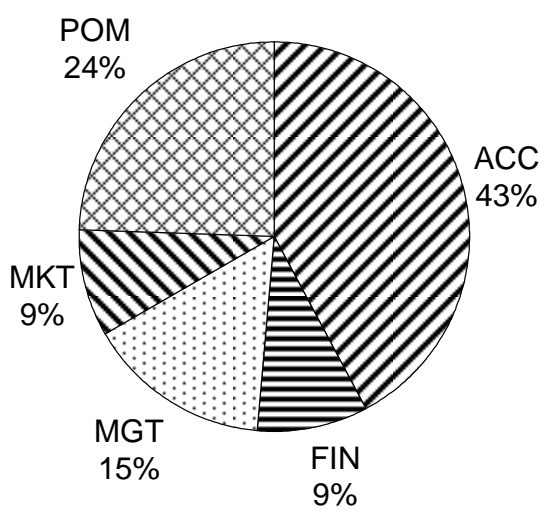

Figure 4. Academic area courses other than MIS

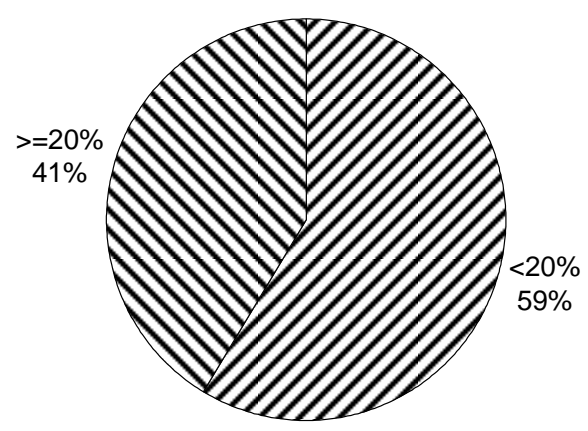

Figure 5. SAP Course content

Only 41 percent of the courses (Figure 5) had an ES or SAP R/3 content that was 20 percent or more. That content could be either ES concepts or SAP R/3 examples of that content. These levels are irrespective of the primary category area or the academic area. Most, 58 percent, of the courses with an ES content of 20 percent or more were found to be in the MIS academic area (Figure 6). There is a significant difference $(\forall=.05)$ for the percent of $R / 3$ content among the academic areas or departments of the course $(\Pi 2, \Delta=0.0162)$. However, for these academic area courses, there is not a significant difference between the MIS and POM areas $(\Pi 2, \Delta=0.7861)$. Whereas a comparison across the primary content areas indicates there is a significant difference $(\forall=.05)$ for the percent of $\mathrm{R} / 3$ content $(\Pi 2, \Delta=0.0182)$. And, a significant difference $(\forall=.05)$ exists between the MIS and functional course areas $(\Pi 2, \Delta=0.0166)$. Clearly, the MIS academic area has courses with the greatest percent $\mathrm{R} / 3$ content.

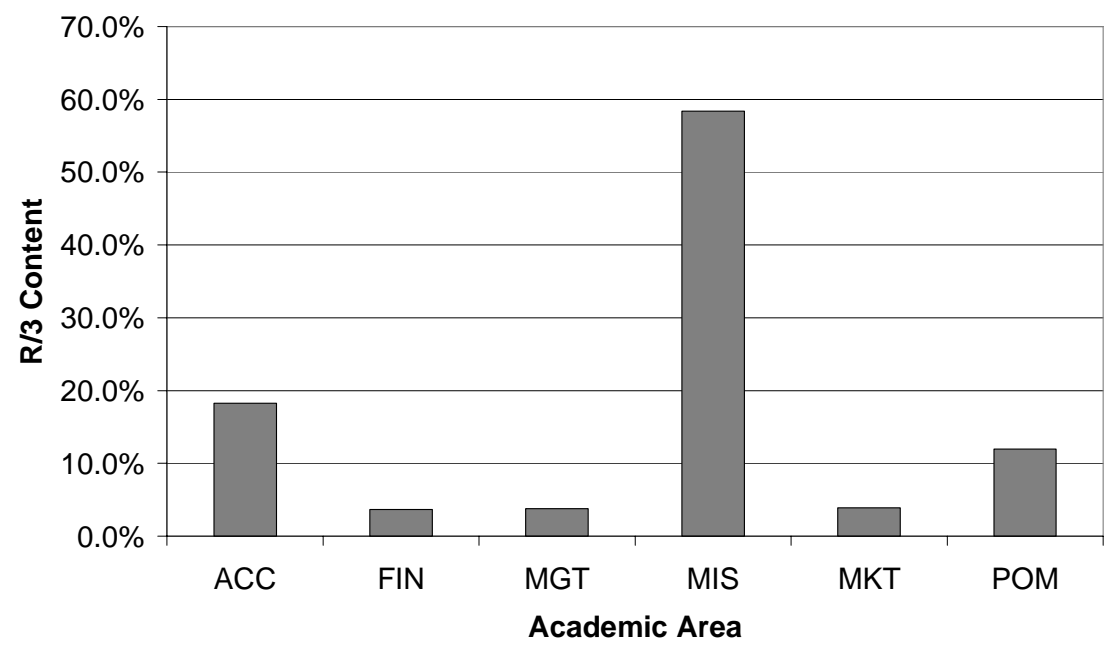

Figure 6. Average percent of $\mathrm{R} / 3$ course content 
Generally, students were quite satisfied with their SAP R/3 course experiences (Figure 7). The average satisfaction was $3.9(\sigma=.08)$. Only four percent of the students reported they were somewhat dissatisfied with the SAP R/3 course content and experience. Figure 8 displays the satisfaction in student satisfaction across the academic areas of the courses. There is not a significant difference $(\forall=.05)$ among the academic areas of the courses ( $\Pi 2, \Delta=0.5349)$. However, when compared across the primary category area courses, there is a significant difference $(\forall=.05)$ among theses course areas $(\Pi 2, \Delta=0.0407)$. On the other hand, there is not a significant difference between the students' satisfaction for the MIS and functional course areas. $(\Pi 2, \Delta=0.0766)$.

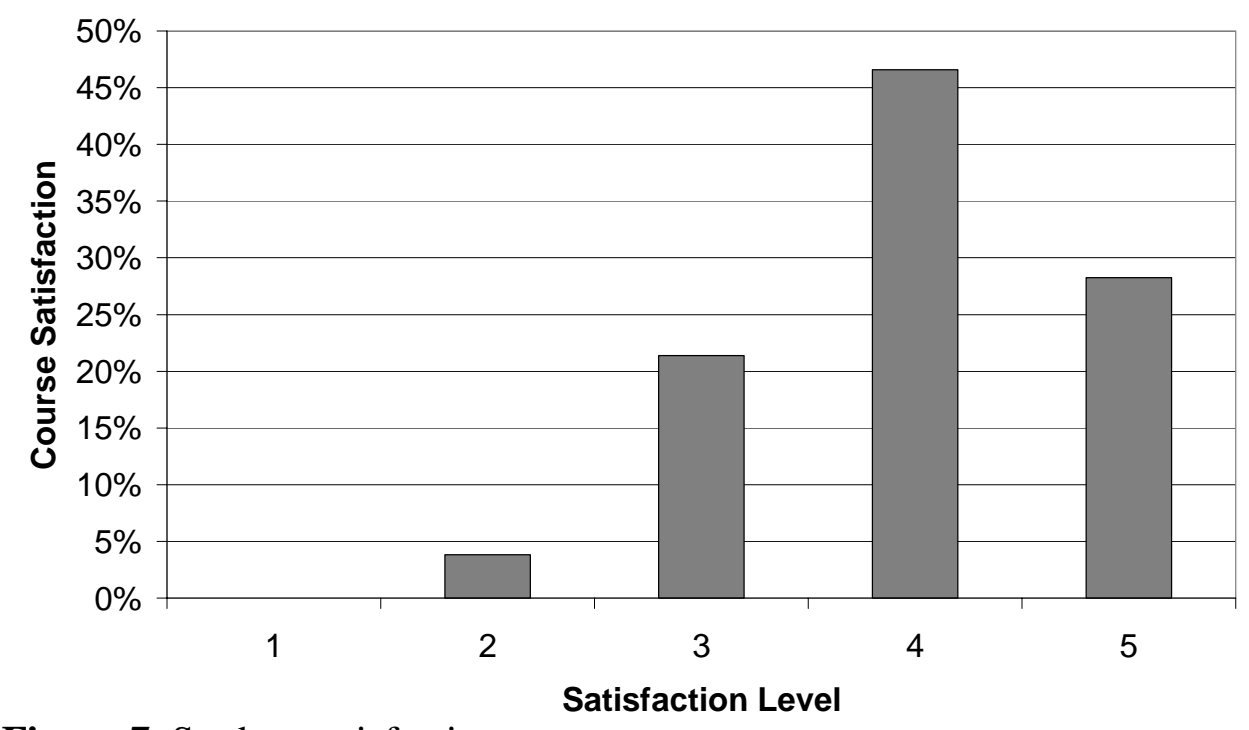

Figure 7. Student satisfaction

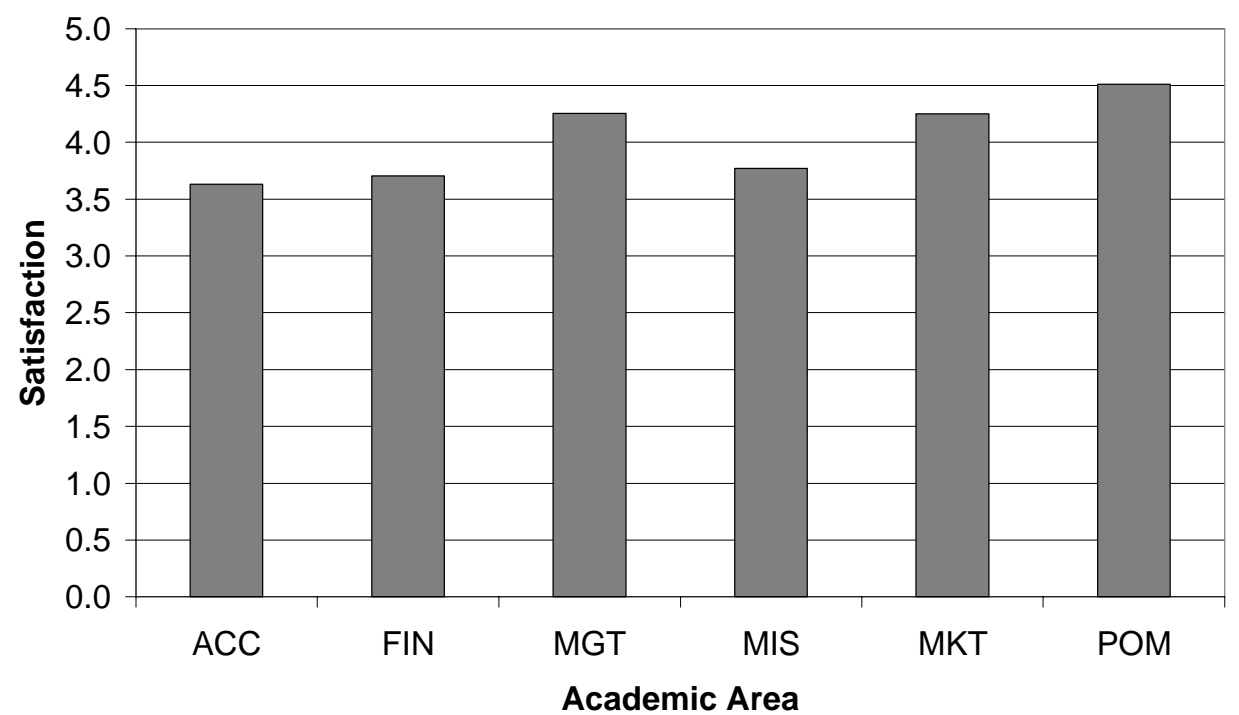

Figure 8. Student satisfaction by academic area 


\section{SUMMARY AND CONCLUSION}

A variety of alternatives are being used to integrate ES into the business and related curriculum. Several frameworks provide guidance for curriculum integration with consideration provided for courses designed for All Students, the Functional Areas, and IS Programs. The actual integration effort to-date is multi-dimensional in the approaches of curriculum integration. The most frequently reported effort is a single course for All Students, which is an introduction to IS. While only 5 percent of the courses are All Students courses, 25 percent of the students reported in the survey have enrolled in these courses. Generally, students have indicated they are satisfied with their courses containing ES content. Less than half the courses reported have an ES content that is 20 percent or more. The MIS academic area houses the All Students courses in addition to the course for their majors. These MIS area courses have the greatest R/3 or ES content as compared to all other academic areas. These results suggest that the integration efforts are being strongly influenced by the MIS academic areas or departments. Therefore, additional attention in curricula development could be directed towards the other functional areas.

\section{REFERENCES}

1. Antonucci, Y. L., Corbitt, G. Stewart, G. \& Harris, A. L. (2004). Enterprise Systems Education: Where Are We/ Where Are We Going? Journal of Information Systems Education, 15(3), 227-234.

2. Corbit, G. \& Mensching, J. (2000). Integrating SAP R/3 into a College of Business curriculum: Lessons learned, Information Technology and Management, 1(4), 247-258.

3. Gust, D. D. \& Hayen, R. L. (1999). Including SAP Enterprise Software in the Introductory Business Computer Course, Proceedings, ISECON, October 1999.

4. Hawking, P., Ramp, A. \& Shackleton, P. (2001). IS ' 97 model curriculum and ERP systems, Business Process Management Journal, 7(3), 225-233.

5. Hawking, P., McCarty, B. \& Stein, A. (2004). Second Wave ERP Education, Journal of Information Systems Education, 15(3), 327-332.

6. Hayen, R. L. \& Andera F. J. (2003). Assessment of Student Satisfaction with SAP R/3 Component Courses, Issues in Information Systems, 4(1), 150-156.

7. Hayen, R. L. \& Cappel, J. J. (2003). Enterprise Software Certification Academy: A Longitudinal Study, Journal of Computer Information Systems, 43(3).

8. Hayen, R. L., Cappel, J. J. \& Holmes, M. C. (1999-2000). A Framework of SAP R/3 Enterprise Software Instruction, Journal of Computer Information Systems, 40(2), 79-85.

9. Hayen, R. L., Holmes, M. C. \& Cappel, J. J. (2000). An SAP R/3 Virtual Classroom for Asynchronous Collaborative and Experiential Learning, Issues in Info Systems, 1, 189-195.

10. Jarmoszko, A. T. \& Gendron, M. (2004). Choosing and ERP-type System for a Belarus Enterprise, Journal of Information Systems Education, 15(3), 255-260.

11. Klaus, J., Rosemann, M. \& Gable, G.G. (2000). What is ERP? Information Systems Frontiers, 2(2), 141-162.

12. McCombs, G. B. \& Sharifi, M. (Winter 2002-2003). Design and Implementation of an ERP Oracle Financials Course, Journal of Computer Information Systems, 43(2), 71-75.

13. SAP AG (2001). What's New with the SAP Educational Alliance Program in the U.S. Philadelphia, PA: SAP America, Inc. September 2001.

14. Strong, D. M., Johnson, S. A. \& Mistry, J. J. (2004). Integrating Enterprise Decision-Making Modules into Undergraduate Management and Industrial Engineering Curricula, Journal of Information Systems Education, 15(3), 301-313. 